\title{
Studi Diagnostik Konservasi Tempat Tidur Etnik Madura Koleksi Museum Kayu Wanagama I
}

\author{
Yustinus Suranto \\ Fakultas Kehutanan Universitas Gadjah Mada \\ email: suranto@ugm.ac.id
}

\begin{abstract}
Abstrak: Kayu merupakan bahan yang terbaik untuk digunakan sebagai bahan dalam pembuatan benda-benda budaya, baik berupa benda fungsional maupun benda untuk mengekspresikan rasa seni. Benda-benda budaya mengandung nilai luhur dalam aspek-aspek: budaya, sosial, arkeologi, sejarah, ilmu pengetahuan dan teknologi serta ekonomi. Benda budaya ada yang tersimpan sebagai koleksi museum. Koleksi museum berfungsi sebagai sarana untuk menyelenggarakan pendidikan dalam suasana rekreasi bagi masyarakat dalam rangka menanamkan nilai-nilai luhur budaya dan jati diri sebagai bangsa yang majemuk serta memupuk rasa bangga sebagai warga Negara Indonesia. Nilai dan fungsi koleksi museum diharapkan dapat memberi inspirasi pemunculan suatu pemikiran baru. Keberadaan koleksi museum wajib dipertahankan, apalagi kayu sangat mudah mengalami kerusakan. Konservasi koleksi museum dan benda cagar budaya bahan kayu mencakup konservasi secara preventif dan kuratif dengan tujuan untuk mempertahankan keberadaan koleksi.

Salah satu koleksi Museum Kayu Wanagama I adalah mebel yang berupa Tempat Tidur Etnik Madura. Koleksi yang diduga sebagai cagar budaya ini telah mengalami kerusakan pada beberapa komponen, sehingga perlu dilakukan tindakan konservasi secara kuratif. Tindakan konservasi wajib dilakukan dengan mengikuti prosedur tertentu, yakni studi diagnostik konservasi dan pelaksanaan konservasi koleksi. Studi diagnostik konservasi kayu terdiri atas lima tahapan, yaitu (1) deskripsi kondisi koleksi pada saat sebelum dilakukan konservasi, (2) deskripsi koleksi dalam kondisi ideal, (3) identifikasi jenis bahan, (4) identifikasi penyebab kerusakan bahan dan (5) perumusan pelaksanaan konservasi koleksi.

Hasil penelitian diagnostik konservasi koleksi menyimpulkan empat hal. Pertama, bagian koleksi yang mengalami degradasi adalah komponen gelagar depan bagian bawah dan komponen rusuk. Kedua, kerusakan komponen disebabkan serangan rayap kayu kering. Ketiga, jenis kayu bahan gelagar dan rusuk adalah jati (Tectona grandis Linn). Keempat, komponen galar terbuat dari bambu telah musnah. Berbasis studi tersebut, pemugaran dilakukan dengan mengganti gelagar bagian depan dan rusuk dengan kayu baru yang kualitasnya sama serta mengadakan komponen galar baru yang terbuat dari bambu.
\end{abstract}

Kata Kunci: Studi diagnostik, Konservasi, Koleksi Museum, Jati.

Abstract: Wood is the best material to use as a raw material to make cultural objects, both functional objects and art objects. Cultural objects contain noble values in aspects of: culture, social, archaeology, history, science and technology, as well as economy. They generally are stored as museum collections. The museum collection serves a mean to provide an education and recreation for the community in order to inculcate noble values of culture and identity as a pluralistic nation and to foster a sense of pride as an Indonesia citizen. Values and functions of the museum collections are expected to inspire and stimulate a new thought. The existence of museum collections shall be maintained, because wood is very susceptible to damage. Conservation of museum collections and wooden cultural heritage objects consist of preventive and curative conservation for the purpose of maintaining its existence.

One of the collections owned by Wanagama I Wood Museum is furniture in the form of Bed of Madura Ethnic. This collection, which was considered as cultural heritage, has been damaged in some parts, so it needs to be curatively conserved. Conservation activity shall be done by a standardized procedures, namely a diagnostic study and then followed by implementation of collection conservation. Diagnostic study on wood conservation consists of five stages, namely (1) a description of the existing conditions of collection prior to conservation, (2) a description of the collection in ideal conditions, (3) an identification of the wood species, (4) identification of the wood defects its causes and (5) the formulation of conservation activities for the museum collection.

The results of diagnostic studies consist of four points. First, front and bottom beam and ribs as part of the bed components were degraded. Second, the degradation of those two collections components were caused by infestation of dry wood termite. Third, wood species as a raw material of beam and ribs components were teak (Tectona grandis Linn). Fourth, 'galar' components made of bamboo has been lost. Based on the study, restoration was performed by replacing front and bottom beam, as well as ribs, and put new galar components, which was made of apus bamboo.

Keywords: Diagnostic studies, Conservation, Wanagama I Museum Collections, Teak, Bamboo 


\section{PENDAHULUAN}

\section{Latar Belakang}

Museum Kayu Wanagama I Fakultas Kehutanan Universitas Gadjah Mada merupakan museum yang seluruh koleksi berbahan dasar kayu. Salah satu koleksi adalah Tempat TidurEtnik Madura. Koleksi ini mengalami kerusakan pada komponen tertentu, sehingga kondisi koleksi menjadi tidak utuh lagi. Koleksi perlu dilakukan konservasi dan pemugaran. Pemugaran koleksi museum dilakukan dengan mengikuti kaidah konservasi arkeologis sebagaimana tertuang dalam UU no 11 tahun 2010 tentang Cagar Budaya, yakni berusaha mempertahankan keaslian dalam hal bahan, bentuk, ukuran dan cara pengerjaan. Untuk memenuhi kaidah konservasi koleksi, penelitian tentang jenis bahan, penyebab kerusakan dan tata cara konservasi perlu dilakukan. Penelitian ini bertujuan untuk mengetahui jenis kayu dan penyebab kerusakan kayu yang menjadi komponen mebel Tempat Tidur Etnik Madura koleksi Museum Kayu Wanagama I, Fakultas Kehutanan Universitas Gadjah Mada. Penelitian dimaksudkan mendapatkan data yang akan digunakan sebagai acuan bagi pelaksanaan pemugaran.

Museum Kayu Wanagama I Fakultas Kehutanan Universitas Gadjah Mada merupakan museum yang seluruh koleksinya berbahan dasar kayu. Salah satu koleksinya adalah Tempat Tidur Etnik Madura. Sebagai koleksi berbahan kayu pada umumnya yang sangat rentan terhadap berbagai jenis kerusakan, koleksi tempat tidur etnik ini juga mengalami kerusakan sehingga kondisinya sebagai koleksi menjadi tidak utuh lagi.

\section{Tujuan Penelitian}

Penelitian ini bertujuan untuk mengetahui jenis kayu dan penyebab kerusakannya pada kayu yang menjadi komponen mebel Tempat Tidur Etnik Madura koleksi Museum Kayu Wanagama I, Fakultas Kehutanan Universitas Gadjah Mada.

\section{Manfaat Penelitian}

Penelitian ini bermanfaat untuk mendapatkan data yang akan digunakan sebagai acuan bagi pelaksanaan konservasi Tempat Tidur Etnik Madura koleksi Museum Kayu Wanagama I, Fakultas Kehutanan Universitas Gadjah Mada.

\section{STUDI PUSTAKA}

\section{Permuseuman}

Berdasarkan definisi yang diberikan International Council of Museums (ICOM), Museum, adalah institusi permanen, nirlaba, melayani kebutuhan publik, dengan sifat terbuka, dengan cara melakukan usaha pengoleksian, mengkonservasi, meriset, mengkomunikasikan, dan memamerkan benda nyata kepada masyarakat untuk kebutuhan studi, pendidikan, dan kesenangan. Oleh karena itu, museum dan benda koleksinya dapat menjadi bahan studi oleh kalangan akademis, dokumentasi kekhasan masyarakat tertentu, ataupun dokumentasi dan pemikiran imajinatif pada masa depan. Sejak tahun 1977, setiap tanggal 18 Mei diperingati sebagai hari Hari Museum Internasional (Wikipedia, tanpa tahun).

Berbagai jenis bahan digunakan sebagai bahan utama untuk membuat koleksi museum, salah satu diantaranya adalah kayu. Kayu merupakan bahan yang terbaik untuk digunakan dalam pembuatan benda-benda budaya, baik berupa benda fungsional untuk menunjang aktivitas hidup sehari-hari maupun benda untuk mengekspresikan rasa seni. Benda budaya pada saat ini ada berupa koleksi museum maupun bangunan yang berstatus sebagai cagar budaya. Benda-benda budaya, termasuk yang disimpan sebagai koleksi di museum, mengandung nilai yang luhur dalam aspek-aspek : budaya, sosial, arkeologi, sejarah, ilmu pengetahuan dan teknologi serta ekonomi. Oleh karenanya, koleksi museum dapat difungsikan sebagai sarana untuk menyelenggarakan pendidikan dalam suasana rekreasi kepada masyarakat, khususnya generasi muda, dalam rangka menanamkan nilai-nilai luhur budaya dan jati diri bangsa Indonesia sebagai bangsa yang majemuk serta memupuk rasa bangga sebagai warga Negara Indonesia. Nilai dan fungsi koleksi museum yang demikian itu dapat memberi inspirasi pemunculan suatu pemikiran dalam tataran nasional maupun internasional. Oleh karena itu, keberadaan koleksi museum wajib dipertahankan. Usaha untuk mempertahankan keberadaan koleksi berbahan kayu mendapat perhatian dan dorongan yang semakin besar, karena kayu sangat mudah mengalami kerusakan yang disebabkan oleh faktor non biotis maupun biotis. Aktivitas yang bertujuan untuk mempertahankan keberadaan koleksi disebut konservasi koleksi/ cagar budaya berbahan kayu, yang mencakup konservasi 
preventif dan kuratif.

\section{Degradasi Kayu}

Semua jenis kayu, baik yang berkualitas tinggi apalagi yang berkualitas rendah, akan mengalami kerusakan. Kerusakan kayu pada umumnya berlangsung secara perlahan-lahan, meskipun ada pula yang berlangsung secara mendadak dalam proses kebakaran. Kerusakan kayu disebabkan oleh berbagai aktor penyebab. Mengingat bahwa penyebab kerusakan kayu sangat beragam, maka diperlukan adanya sistematisasi. Dalam konteks ini, aktor penyebab kerusakan kayu dikelompokkan menjadi dua kelompok utama, yakni (1) penyebab yang berupa faktor lingkungan dan (2) penyebab yang berupa faktor biotik.

Faktor lingkungan yang menjadi penyebab kerusakan kayu dibedakan lebih lanjut menjadi empat macam, yaitu cuaca, panas dan api, beban mekanis dan bahan kimia. Sementara itu, faktor biotik penyebab kerusakan kayu dibedakan lebih lanjut menjadi dua golongan, yaitu organisme mikro dan binatang. Golongan organisme mikro perusak kayu meliputi cendawan dan bakteri. Agen perusak kayu berupa binatang dibedakan lebih lanjut menjadi dua kelompok, yaitu binatang yang hidup di darat dan binatang yang hidup di laut. Binatang yang hidup di darat akan merusak kayu yang ada di darat. Binatang yang hidup di darat dibedakan lebih lanjut menjadi tiga kelompok, yaitu (1) kelompok rayap (isoptera), (2) kelompok kumbang bubuk (coleoptera) dan (3) kelompok semut dan lebah (bymenoptera) (Subyanto, 2006). Sebaliknya, binatang yang hidup di laut akan merusak cagar budaya berbahan kayu (CBBK) yang ada di laut. Binatang laut dibedakan lebih lanjut menjadi dua kelompok, yaitu (1) kelompok mollusca, dan (2) kelompok crustacea.

Setiap degradator merusak kayu dengan cara yang unik, sehingga degradator yang satu berbeda terhadap degradator yang lain dalam hal cara merusak kayu. Keunikan tersebut dapat dilihat dari aspek komponen kimia kayu yang dirusak maupun mekanisme perusakan terhadap komponen kimia kayu tersebut. Mekanime perusakan komponen kimia kayu dapat berlangsung dengan pola depolimerisasi komponen kimia kayu, atau pola konsumsi terhadap komponen kimia kayu atau pola degradasi lainnya.
Kayu tersusun atas suatu matriks atau kerangka yang terdiri atas unsur-unsur kimia kayu, yaitu selulosa, hemiselulosa dan lignin. Meskipun fungsi setiap unsur kimia itu tidak dapat dipilah secara tegas, unsur selulosa dan hemiselulosa mengakibatkan kayu memiliki kekuatan, sedangkan unsur lignin mengakibatkan kayu memiliki kelenturan atau kekakuan dan kekerasan. Di samping matrik yang terdiri atas selulosa, hemiselulosa dan lignin, kayu juga mengandung zat ekstraktif dan pati. Zat ekstraktif merupakan zat yang mengakibatkan kayu memiliki sifat keawetan alami, sifat pewarnaan dan kilap. Zat ekstraktif dapat diekstrak atau dikeluarkan dari kayu tanpa merusak matriks kayu. Dengan demikian, kayu masih memiliki kekuatan dan kekerasan meskipun zat ekstraktif telah dikeluarkan dari kayu (Shmulsky dan Jones, 2011).

Sementara itu, pati merupakan zat hasil fotosintesis yang disimpan dalam jaringan parenkim kayu dan berfungsi sebagai cadangan makanan bagi pohon. Pada saat tertentu, pati diubah menjadi energi demi penyelenggaraan proses fisiologi pohon dalam rangka menyelenggarakan aktivitas hidupnya. Pada saat yang lain, pati disintesis dan dipolimerisasikan oleh pohon itu untuk membentuk selulosa, hemiselulosa, lignin maupun zat ekstraktif dalam rangka pertumbuhan diri pohon dan menambah ukuran pohon itu, baik tumbuh secara meninggi maupun tumbuh secara membesar (Shmulsky dan Jones, 2011). Di samping itu, kayu juga tersusun dari satu lagi unsur kimia kayu, yaitu zat mineral kayu. Zat mineral akan tersisa sebagai abu apabila kayu terbakar.

Berdasarkan jenis komponen kimia kayu yang dirusak, maka degradator dapat dikelompokkan menjadi dua. Kelompok pertama adalah degradator yang mengkonsumsi pati sehingga merusak kayu yang mengandung pati. Kelompok kedua adalah kelompok degradator yang merusak matriks kayu, yaitu selulosa, hemiselulosa dan lignin. Degradator yang mengkonsumsi pati dan merusak kayu adalah kelompok kumbang bubuk (coleoptera) dan bakteri. Sebaliknya, degradator yang mengkonsumsi selulosa, hemiselulosa atau lignin sehingga merusak kayu adalah seluruh degradator yang bukan kelompok kumbang bubuk (coleoptera) dan bakteri (Nicholas, 1973). 


\section{Konservasi Koleksi}

Dari uraian di atas, menjadi jelaslah bahwa sebagai salah satu jenis bahan dasar penyusun utama CBBK, kayu merupakan bahan organik hasil pohon yang rentan terhadap kerusakan dan dekomposisi, baik yang disebabkan oleh unsur biotis maupun non-biotis. Oleh karena itu, upaya untuk mempertahankan keberadaan benda cagar budaya berbahan kayu perlu dilakukan. Upaya ini diwujudkan dalam aktivitas pelestarian benda cagar budaya. Pelestarian dilakukan dalam berbagai bentuk aktivitas. Aktivitas yang tercakup di dalamnya meliputi pemeliharaan, perawatan, dan pemugaran. Aktivitas pemeliharaan dilakukan antara lain dengan membersihkan CBBK dari kotoran debu dan sampah. Aktivitas perawatan dilakukan antara lain dengan mengusahakan agar komponen penyusun CBBK berada pada posisi yang seharusnya, sehingga fungsi komponen tersebut dapat diaktualisasikan secara penuh. Aktivitas pemugaran dilakukan dengan membangun kembali CBBK sesuai dengan kondisinya yang asli (Anonim, 2012). Oleh karena itu, aktivitas pemugaran dilakukan bila CBBK itu mengalami kerusakan yang cukup parah. Di dalam aktivitas pemugaran, ada kemungkinan yang sangat besar untuk mengganti komponen tertentu atas CBBK dan komponen ini berbahan kayu.

Penggantian kayu sebagai komponen CBBK dilakukan dengan berpedoman ketat terhadap persyaratan dan aturan-aturan tertentu sesuai dengan ketentuan yang tercantum di dalam Undang-Undang No 11 tahun 2010 tentang Cagar Budaya. Hal ini dimaksudkan agar CBBK hasil pemugaran tetap terjaga otentisitasnya. Untuk mewujudkan otentisitas itu, penggantian kayu bagi pemugaran CBBK memerlukan persyaratan berupa keaslian jenis kayu, keaslian asal kayu, kesesuaian umur pohon penghasil kayu. Di samping itu, penggantian kayu komponen CBBK juga memenuhi beberapa aturan, yakni kesesuaian sortimen kayu, kesesuaian bentuk dan ukuran kayu, serta kesesuaian proses pengerjaan. Dengan kata lain, apabila kayu sebagai komponen penyusun bangunan CBBK itu harus diganti karena mengalami kerusakan, maka kayu baru sebagai pengganti komponen penyusun bangunan CBBK harus memiliki jenis yang sama, berasal dari wilayah yang sama, pohon penghasil kayu tersebut memiliki umur yang sama, sortimen kayu pengganti memiliki bentuk dan ukuran yang sama, serta kayu itu harus dikerjakan dengan alat yang sama dan metode pengerjaan yang sama dengan jenis kayu yang digantikannya (Presiden RI, 2010).

Oleh karena penggantian kayu sebagai komponen CBBK memerlukan otentisitas, maka aktivitas pemugaran harus dikelola secara seksama dan rapi. Di dalam konteks ini, pengelolaan terhadap aktivitas pemugaran selalu dilakukan dengan beberapa langkah secara berurutan. Pertama, proses pemugaran selalu diawali dengan aktivitas observasi dalam rangka mengamati dan mencatat segala hal yang berkait dengan aktivitas pemugaran. Kedua, proses identifikasi dan analisis. Langkah kedua ini dimaksudkan untuk mengidentifikasi segala sesuatu, kemudian menganalisisnya agar pemugaran dapat dilakukan dengan menjaga otentisitas. Di dalam konteks ini, identifikasi dan analisis kayu yang akan diganti merupakan hal yang sangat penting. Ketiga, adalah perencanaan penanganan. Di dalam perencanaan penanganan ini, seluruh sumber daya pemugaran dideskripsikan dan direncanakan. Keempat, pelaksanaan aktivitas pemugaran tersebut (Presiden RI, 2010).

\section{Identifikasi Kayu}

Jenis kayu dapat ditentukan melalui aktivitas identifikasi kayu. Aktivitas ini dilakukan dengan melakukan pengamatan terhadap struktur makroskopis kayu dan/ atau anatomi kayu. Pengamatan struktur makroskopis kayu diarahkan untuk mengenal komponen-komponen seluler penyusun kayu yang dilakukan dengan cara mengamati struktur kayu dan tekstur kayu. Komponen sel-sel penyusun kayu meliputi serabut, trakeid, pembuluh, jari-jari, parenkim, dan saluran damar. Struktur kayu mempelajari tentang keberadaan, posisi dan konfigurasi komponen sel-sel penyusun kayu. Secara makroskopis, konfigurasi ini membentuk lingkaran pertumbuhan, kayu gubal-kayu teras, kayu awal-kayu akhir. Tekstur kayu mempelajari secara makro tentang dimensi ukuran komponen sel-sel penyusun kayu, sehingga dikenal kayu bertekstur halus, sedang dan kasar. (Soenardi, 1977).

Ilmu struktur kayu juga mempelajari keanekaan atau keragaman konfigurasi yang terbentuk oleh jaringanjaringan komponen penyusun kayu. Konfigurasi jaringanjaringan ini membentuk pola tertentu. Pola tertentu ini berkait dengan unsur genetis dari jenis kayu, sehingga jenis kayu tertentu akan memiliki pola tertentu. Oleh 
karena itu, setiap konfigurasi itu dapat dijadikan dasar untuk menentukan jenis kayu, karena setiap jenis kayu memiliki konfigurasi jaringan kayu yang unik dan spesifik. Hal ini berarti bahwa konfigurasi tertentu atas jaringanjaringan tersebut hanya dimiliki oleh jenis kayu tertentu pula. Dengan demikian, Pola konfigurasi jaringanjaringan sel penyusun kayu dapat dijadikan dasar untuk mengidentifikasi jenis kayu (Soenardi, 1977).

\section{METODOLOGI PENELITIAN}

\section{Bahan Penelitian}

Bahan penelitian berupa koleksi Museum Kayu Wanagama I berupa Tempat tidur Etnik Madura. Koleksi ini perlu dipugar karena kondisi sudah mengalami kerusakan yang akut.

\section{Tempat dan Waktu Penelitian}

Tempat penelitian di Laboratorium Pengeringan dan Pengawetan Kayu dan Laboratorium Sifat-sifat Dasar Kayu Bagian THH Fakultas Kehutanan, serta Museum Kayu Wanagama I. Penelitian dimulai awal Juni 2013 dan selesai pada akhir bulan Nopember 2013.

\section{Metode Penelitian}

Konservasi Koleksi Tempat Tidur Etnik Madura dilakukan dengan enam langkah berikut.

1. Penelitian tentang pemotretan, penggambaran dan pengukuran dimensi fisik koleksi beserta bagianbagian sebagai komponen koleksi

2. Penelitian tentang komponen yang mengalami kerusakan.

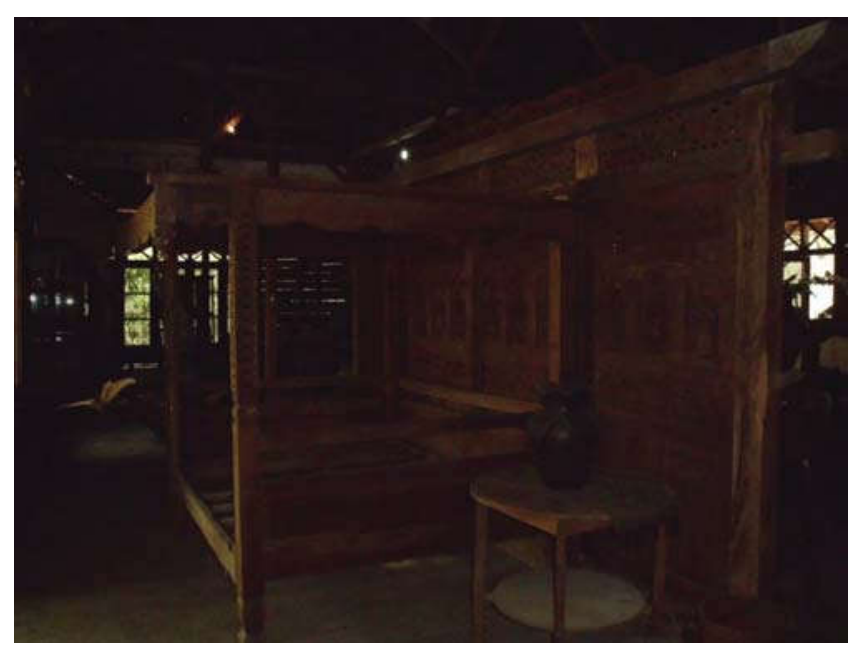

Gambar 1.Tempat Tidur Etnik Madura Koleksi Museum Kayu Wanagama I
3. Penelitian tentang penyebab kerusakan kayu pada komponen yang mengalami kerusakan.

4. Penelitian tentang jenis dan kualitas kayu yang menjadi bahan penyusun komponen yang rusak. Penentuan kualitas kayu didasarkan pada parameter dimensi lebar lingkaran tahun

5. Perumusan strategi pemugaran terhadap koleksi tersebut.

6. Pemugaran sesuai dengan strategi yang telah dirumuskan.

\section{HASIL PENELITIAN DAN PEMBAHASAN}

Hasil penelitian dipilah menjadi lima bagian, yaitu (1) data tentang dimensi fisik dan komponen koleksi yang mengalami kerusakan, (2) data tentang jenis kayu penyusun koleksi, (3) data tentang penyebab kerusakan kayu pada koleksi, (4) strategi konservasi dan (5) aktivitas konservasi. Dengan serangkaian aktivitas tersebut, maka koleksi tempat tidur etnik Madura ini akan menjadi utuh kembali.

\section{Dimensi Koleksi}

Koleksi tempat tidur etnik Madura yang dimiliki oleh Museum Kayu Wanagama I terdiri atas komponen berupa gelagar membujur, gelagar melintang, tiang, rusuk, penahan kasur, gelaran, dan unsur dekorasi. Koleksi ini memiliki dimensi panjang $204 \mathrm{~cm}$, lebar $163 \mathrm{~cm}$ dan tinggi $196 \mathrm{~cm}$. Secara keseluruhan, foto tempat tidur etnik Madura itu disajikan pada Gambar 1, sedangkan dimensi komponen secara skematik disajikan pada Gambar 2. Sementara itu, dimensi komponen secara riil disajikan pada Tabel 1.

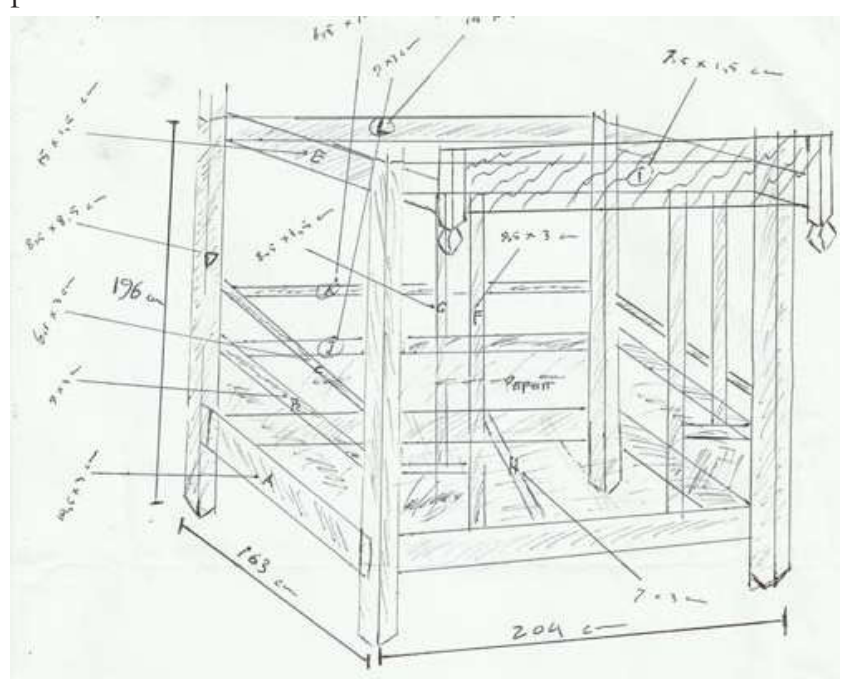

Gambar 2. Dimensi Komponen Tempat Tidur Secara Skematik 
Tabel 1. Dimensi Komponen Tempat Tidur Koleksi Museum Kayu Wanagama I

\begin{tabular}{|c|c|c|c|c|c|}
\hline & \multirow{2}{*}{ Nama Komponen } & \multicolumn{3}{|c|}{ Dimensi (cm) } & \multirow{2}{*}{$\begin{array}{l}\text { Jumlah } \\
\text { (satuan) }\end{array}$} \\
\hline & & Panjang & Lebar & Tebal & \\
\hline Soko & & 196 & 8,5 & 8,5 & 4 \\
\hline \multirow[t]{5}{*}{ Bagian Kaki } & Gelagar melintang depan & 204 & 9 & 3 & 1 \\
\hline & Gelagar melintang belakang & 204 & 15 & 1,5 & 1 \\
\hline & Gelagar membujur & 163 & 14,5 & 3 & 2 \\
\hline & Gelagar membujur atas & 163 & 4 & 3 & 2 \\
\hline & Rusuk membujur & 163 & 7 & 3 & 7 \\
\hline \multirow[t]{6}{*}{ Bagian Badan } & Rusuk melintang bawah & 204 & 9 & 3 & 1 \\
\hline & Rusuk melintang atas & 204 & 6,5 & 3 & 1 \\
\hline & Rusuk membujur bawah & 163 & 9 & 3 & 2 \\
\hline & Rusuk membujur atas & 163 & 6,5 & 3 & 2 \\
\hline & Rusuk tegak utama depan & 166 & 9,5 & 3 & 2 \\
\hline & Rusuk tegak pengiring depan & 130 & 8,5 & 1,5 & 2 \\
\hline \multirow[t]{4}{*}{ Bagian Mahkota } & Gelagar melintang depan & 204 & 7,5 & 1,5 & 1 \\
\hline & Gelagar melintang belakang & 204 & 15 & 1,5 & 1 \\
\hline & Gelagar membujur & 163 & 15 & 1,5 & 2 \\
\hline & Dekorasi & 20 & 5 & 5 & 2 \\
\hline
\end{tabular}

\section{Kerusakan Komponen Koleksi}

Seluruh komponen konstruksi koleksi yang mengalami kerusakan, baik kerusakan yang bersifat berat maupun yang bersifat ringan. Komponen yang mengalami
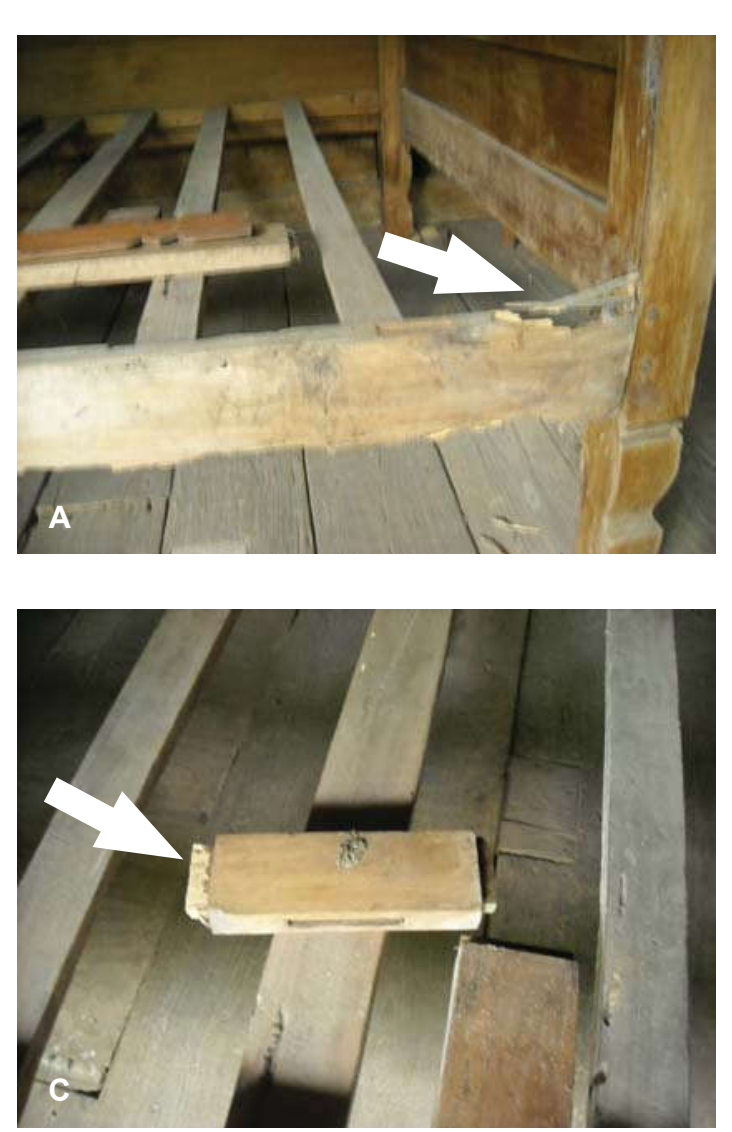

kerusakan berat ada dua bagian, yaitu (1) kondisi lapuk gelagar utama bagian depan bagian bawah dan (2) pecah pada ujung rusuk-rusuk penyangga galar. Sementara itu, kerusakan tingkat sedang dialami oleh bagian purus
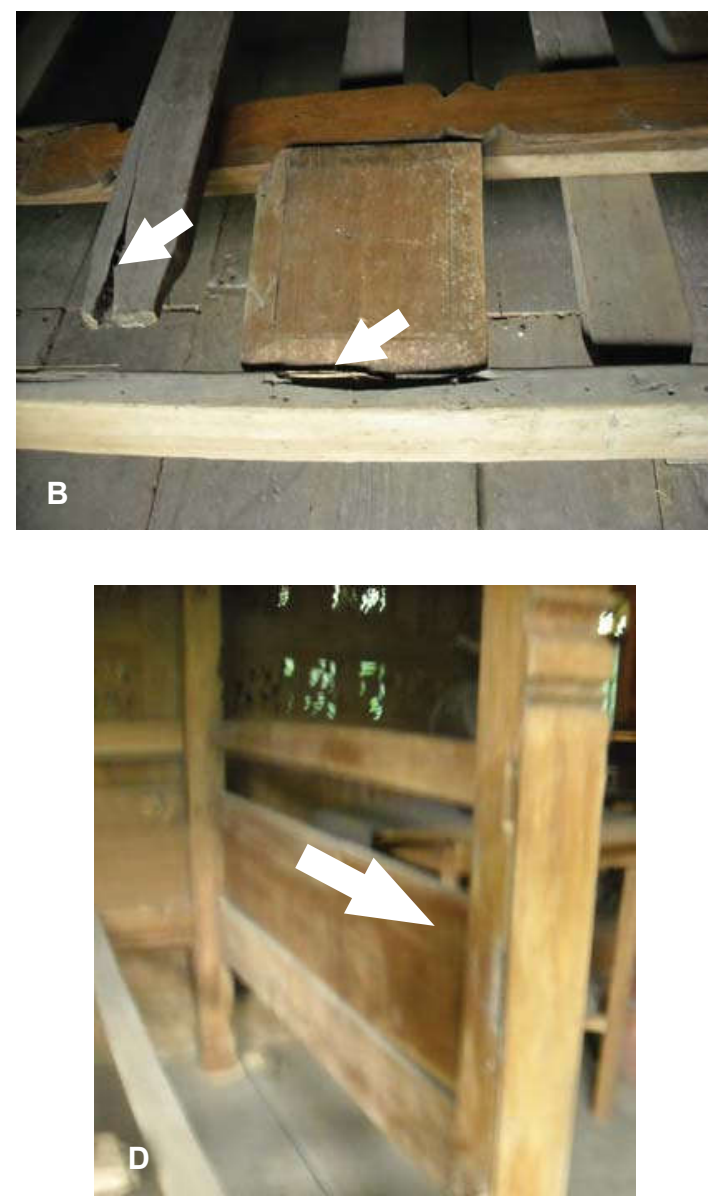

Gambar 3. (a) Lapuk pada Gelagar Depan (c) Lapuk pada Purus Dinding, (b) Pecah pada rusuk dan Lapuk pada Gelagar Depan

(d) Kilap Pudar pada Seluruh Komponen Tempat Tidur 
komponen dinding depan dan kerusakan ringan dialami oleh seluruh komponen koleksi. Kerusakan ringan terutama berupa faktor non biotis berupa memudarnya kilap kayu, sehingga kayu menjadi suram dan tidak lagi mengkilap. Kondisi kerusakan itu disajikan pada Gambar 3 berikut.

\section{Penyebab Degradasi Kayu}

Banyak butiran berwarna kecoklatan dan berukuran kecil berbentuk poligonal yang berserakan di bawah koleksi, tepatnya pada lantai yang berada tepat di bawah gelagar depan bagian bawah. Butiran ini disajikan dalam Gambar 4 disamping.

Pengamatan terhadap bentuk dan dimensi butiran ini mengarahkan pada kesimpulan, bahwa butiran ini merupakan faeces dari rayap kayu kering. Oleh karena itu, dapat disimpulkan bahwa degradasi kayu pada komponen ini disebabkan oleh serangan rayap kayu kering.

Seluruh komponen konstruksi koleksi yang mengalami kerusakan yang bersifat ringan. Kerusakan ringan ini terutama berupa memudarnya kilap kayu, sehingga kayu menjadi suram dan tidak lagi mengkilap. Hal itu disebabkan oleh faktor non biotis, yakni perubahan faktor cuaca yang berlangsung secara siklis dan berlangsung dalam durasi waktu yang sangat lama.

\section{Identifikasi Jenis Kayu Penyusun Koleksi}

Untuk mengidentifikasi kayu, diambil contoh uji komponen gelagar depan bagian bawah dan komponen rusuk. Contoh uji komponen gelagar diiris pada penampang melintang dan difoto secara makroskopis. Di samping itu, juga diukur dimensi lebar lingkaran tahun untuk sebagai parameter untuk menentukan kualitas kayu. Hasilnya disajikan pada Gambar 5 disamping.

Hasil pengamatan ciri-ciri struktur kayu terhadap contoh uji koleksi dapat dideskripsikan sebagai berikut.

a. Lingkaran tahun tampak jelas. Ada dua penyebab penampakan lingkaran tahun, yaitu (1) adanya parenkim terminal, dan (2) susunan pembuluh dalam susunan tata lingkar semu.

b. Pembuluh berpenyebaran tunggal. Pembuluh tersusun di dalam susunan pori tata lingkar semu. Pembuluh berisi endapan puth kapur.

c. Parenkim bertipe paratrakheal (parenkim yang

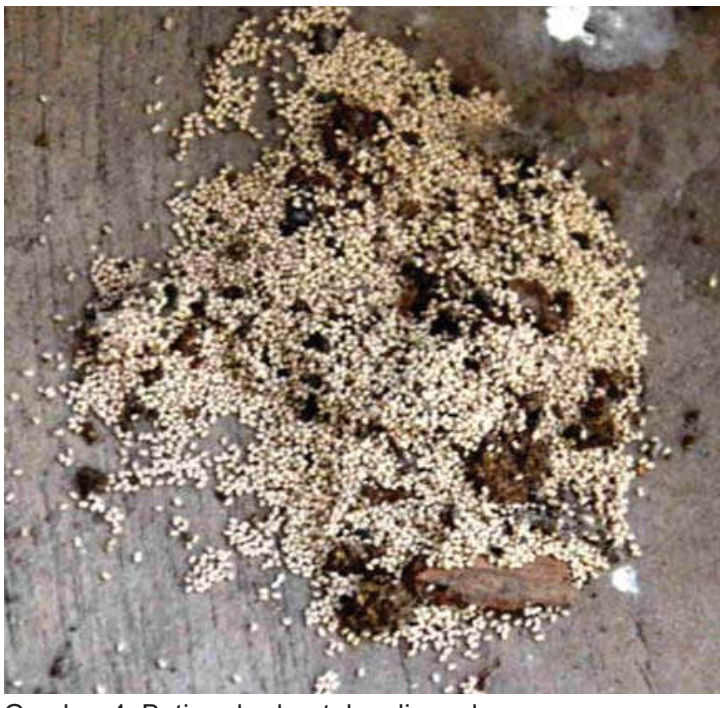

Gambar 4. Butiran berbentuk poligonal

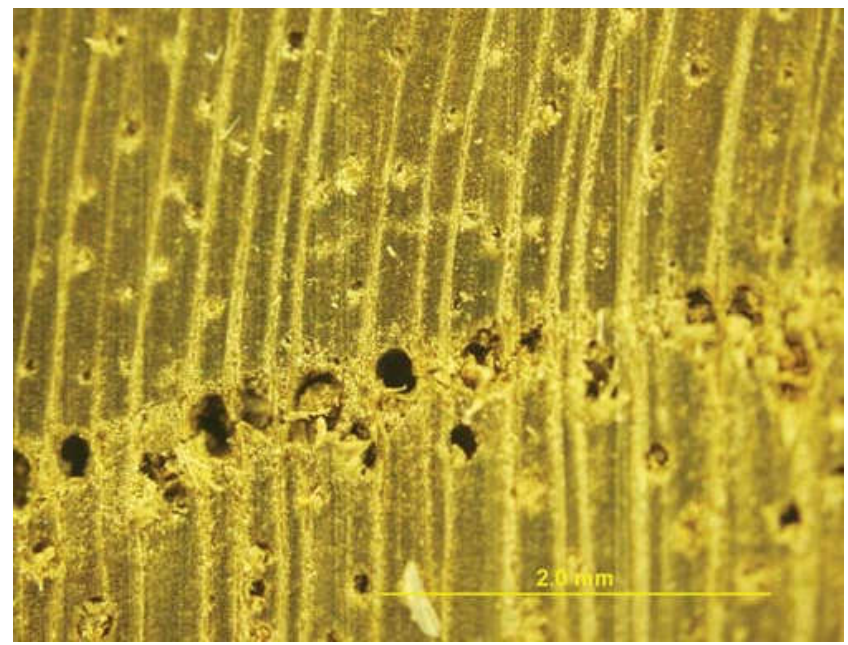

Gambar 5. Penampang Melintang Komponen Gelagar.

bersinggungan dengan pembuluh) dan apotrakheal (parenkim yang tidak berhubungan dengan pembuluh) terdapat pada kayu ini. Parenkim paratrekheal meliputi parenkim vasisentrik (yaitu parenkim yang menyelubungi secara penuh atau lengkap terhadap pembuluh) dan parenkim abaksial (yaitu parenkim yang menyelubungi sebagian saja terhadap pembuluh). Di samping itu, juga terdapat parenkim apotrakheal berupa parenkim inisial (yaitu parenkim yang berada pada bagian awal dari kayuawal) dan parenkim tangensial bentuk pita yang berukuran pendek, meskipun ada pula parenkim bentuk pita tangensial yang berukuran agak panjang.

d. Jari-jari pada penampang $(\mathrm{x})$ dan ( $\mathrm{t}$ ) tampak oleh mata sebagai jari-jari homogen, hanya memiliki satu ukuran, sehingga jari-jari tidak memiliki dua macam ukuran dan bukan jari-jari bertingkat. 
e. Kayu ini memiliki tekstur kayu yang sedang dan agak kasar.

f. Serat pada kayu ini memiliki arah serat yang lurus.

g. Saluran damar tidak terdapat pada sampel kayu ini.

Berdasarkan deskripsi ciri-ciri struktur kayu tersebut di atas, maka dapat ditelusuri dan disimpulkan bahwa contoh-uji kayu ini merupakan jenis kayu jati. Kesimpulan ini diperkuat oleh kesesuaian foto makroskopis penampang melintang contoh uji tersebut dengan foto makroskopis penampang melintang yang terdapat pada Gambar nomor 1271 buku Atlas of Hardwood (Ilic, 1991). Gambar bernomor 1271 ini menunjuk Tectona grandis, yang merupakan nama ilmiah bagi jati. Dengan demikian, kayu yang berfungsi sebagai gelagar atau balok melintang adalah kayu jati.

Hasil pengukuran dimensi lingkaran tahun adalah sebagai berikut. Jumlah lingkaran tahun ada 13. Dimensi lebar masing masing lingkaran tahun adalah 13, 12, 1, 1, 9, 4, 11, 10, 11, 8, 5, 5 dan $4 \mathrm{~mm}$. Dengan demikian, dimensi lebar lingkaran tahun rata-rata adalah 7,25 $\mathrm{mm}$.

Kayu yang menjadi bahan komponen rusuk juga dilakukan identifikasi dengan prosedur yang sama dengan prosedur identifikasi jenis kayu komponen gelagar. Identifikasi ini menghasilkan hasil yang sama dengan identifikasi terhadap kayu gelagar. Dengan demikian, jenis kayu penyusun komponen rusuk ini juga kayu jati. Hasil pengukuran dimensi lingkaran tahun adalah sebagai berikut. Jumlah lingkaran tahun ada 14. Dimensi lebar masing masing lingkaran tahun adalah 11, 7, 5, 0,33, 0,33, 0,33, 1, 1, 8, 8, 9, 6, 4, 8. Dengan demikian, dimensi lebar lingkaran tahun kayu komponen rusuk adalah 4,92 mm.

\section{Strategi Konservasi}

Strategi konservasi koleksi adalah skenario yang merupakan cetak biru di dalam kerangka melakukan aktivitas pelestarian benda cagar budaya. Di dalamnya berisi deskripsi tentang berbagai bentuk aktivitas yang meliputi pemeliharaan, perawatan, dan pemugaran.

Aktivitas pemeliharaan dilakukan dengan membersihkan koleksi dari kotoran debu. Aktivitas perawatan dilakukan dengan mengusahakan agar komponen penyusun CBBK berada pada posisi yang normal, sehingga fungsi komponen dapat diaktualisasikan sebagaimana semula. Aktivitas pemugaran dilakukan dengan membangun kembali koleksi sesuai dengan kondisi yang asli. Oleh karena itu, aktivitas pemugaran dilakukan terhadap komponen koleksi mengalami kerusakan yang cukup parah. Di dalam aktivitas pemugaran, ada proses penggantian komponen gelagar depan bagian bawah dan komponen rusuk. Di samping itu, juga dilakukan pengadaan galar yang terbuat dari bambu apus (Gigantochloa apus Kurz). Hal ini dilakukan, karena galar tersebut telah musnah.

\section{Aktivitas Konservasi.}

Aktivitas konservasi koleksi meliputi pemeliharaan, perawatan, dan pemugaran. Aktivitas pemeliharaan dilakukan dengan membersihkan koleksi dari kotoran debu. Aktivitas perawatan dilakukan dengan mengusahakan agar komponen penyusun koleksi berada pada posisi yang ideal, sehingga fungsi komponen tersebut dapat diaktualisasikan secara penuh. Dalam konteks ini, ada pembenahan terhadap rusuk penyangga dan komponen dinding bagian depan serta komponen penyangga kelambu.

Aktivitas pemugaran dilakukan dengan membangun kembali koleksi sesuai dengan kondisinya yang asli. Aktivitas pemugaran dilakukan terhadap komponen koleksi itu mengalami kerusakan yang cukup parah. Di dalam konteks ini, dilakukan proses penggantian terhadap: (1) komponen gelagar bawah depan, (2) tiga buah komponen rusuk penyangga galar, (3) penggantian komponen gelagar bawah depan dan rusuk penyangga galar dilakukan dengan memilih kayu yang kualitasnya sama atau mendekati, yang ditentukan berdasarkan ratarata dimensi lebar lingkaran tahun pada masing-masing komponen tersebut, yakni 7,25 $\mathrm{mm}$ dan 4,92 $\mathrm{mm}$, dan (4) penggadaan galar yang baru yang terbuat dari bambu. Hal ini disebabkan karena galar dalam kondisi yang tidak tersedia lagi atau telah hilang.

\section{KESIMPULAN DAN SARAN}

Hasil penelitian menyimpulkan lima hal sebagai berikut.

1. Koleksi tempat tidur etnik Madura memiliki dimensi panjang 204, lebar 163 dan tinggi $196 \mathrm{~cm}$

2. Komponen konstruksi koleksi yang mengalami kerusakan berat adalah (1) gelagar utama bagian depan bawah dan (2) rusuk-rusuk penyangga galar. Kerusakan ringan diderita oleh seluruh komponen 
koleksi.

3. Kerusakan berat pada komponen koleksi disebabkan oleh serangan rayap kayu kering, kerusakan ringan disebabkan faktor lingkungan, yaitu fluktuasi suhu dan kelembaban udara.

4. Jenis kayu penyusun gelagar utama dan rusuk penyangga galar sebagai komponen koleksi adalah Jati (Tectona grandis Linn).

\section{DAFTAR PUSTAKA}

Anonim, 2012. Pemugaran Cagar Budaya. Sumber: http:/ / pemugarancagarbudaya.blogspot. com/ Diunggah oleh Januardi, K. Diunduh 13 Oktober 2013.

Ilic, J. 1991. CSIRO Atlas of Hardwood. Crawfor House Press. Melbourne. Australia.

Nicholas, D.D., 1973. Wood Degradation and Its Prevention by Preservative Treatments. Volume I. Degradation and Wood Protection. Syracuse University Press. New York.

Presiden Republik Indonesia, 2010. Undang-undang Republik Indonesia Nomor 11 tahun 2010 tentang Cagar Budaya. Lembaran Negara Republik Indonesia.

Shmulsky, R dan Jones, D., 2011. Forest Product and Wood Science. An Introduction. 6 edition. Wiley-Blackwell Publication. United Kingdom.
5. Aktivitas konservasi dilakukan dengan pemeliharaan, perawatan, dan pemugaran. Pemugaran dilakukan dengan mengganti komponen (1) gelagar utama bawah bagian depan, (2) rusuk-rusuk penyangga galar, dan (3) pengadaan galar baru terbuat dari bambu apus.

Soenardi, 1977. Ilmu Kayu. Yayasan Pembina Fakultas Kehutanan, Universitas Gadjah Mada. Yogyakarta.

Subyanto, 2006. Kemunduran Kualitas Kayu oleh Serangga Perusak Kayu. Fakultas Kehutanan Universitas Gadjah Mada. Yogyakarta.

Suranto, Y., 2006. Kemunduran Kualitas Kayu oleh Faktor Lingkungan Non-Biotis. Fakultas Kehutanan Universitas Gadjah Mada.

Yogyakarta.

Wikipedia, tanpa tahun. Museum. Sumber: http:// en.wikipedia.org/wiki/Museum. Diunduh 12 November 2013. 